\title{
Dichlorvos (DDVP) residue removal from tomato by washing with tap and ozone water, a commercial detergent solution and ultrasonic cleaner
}

\author{
Ali HESHMATI ${ }^{1 *}$, Fatemeh NAZEMI ${ }^{2}$
}

\begin{abstract}
Dichlorvos (DDVP) is one of the most consumption chlorinated organophosphate insecticide used on tomato. The knowledge about the influence of postharvest household processes on the levels of DDVP residues in vegetables is required to estimate dietary exposure. In this study, the removal of sprayed dichlorvos (DDVP) on tomato by washing with tap, ozonated water (in dosages of 2, 4 and $6 \mathrm{mg}$ ozone/L), a commercial detergent solution (in concentration of 1,2 and 3\%) and ultrasonic cleaner (with power of 100, 200 and $300 \mathrm{~W}$ ) was investigated. DDVP residue was determined by gas chromatography with electron capture detector. Washing processes led to the significant reduction of DDVP. The gradual increase in the percentage of the removal was observed due to increment of washing time, ozone dosage, and concentration of detergent solution as well as ultrasonic power. The maximum removal percentage of DDVP after 15 min of washing with tap and ozonated water, a detergent solution and ultrasonic cleaner was 30.7, 91.9, 70.7, and $88.9 \%$, respectively. In general, results indicated washing with tap, ozonated water, a detergent solution and ultrasonic cleaning are effective methods for removal of DDVP from tomato and reduction of its dietary exposure without influence on product quality.
\end{abstract}

Keywords: dichlorvos; pesticide; ozone; ultrasonic; tomato.

Practical Application: Washing processing especially by ozonated water was a suitable method for DDVP removal in tomato.

\section{Introduction}

Pesticides have made high contributions in the mass production of agriculture crops, increasing their quality as well as enhancing and stabilizing crop yield (Nakano et al., 2016). However, the widespread application of pesticide in the current years, especially in some countries has created serious concerns about adverse effects of these substances on the environment and threat of human health (Miele et al., 2015). In the past decades, organophosphorous pesticides in agriculture have been applied more than other pesticides due to low environmental stability and high efficiency (Bai et al., 2006).

Dichlorvos, 2, 2-dichlorovinyl-O, O-dimethyl phosphate (DDVP), is one of the widely consumed chlorinated organophosphate insecticide. This pesticide is applied to control insect pests on vegetable and agriculture products, especially in greenhouses, and buildings, on stored substances and livestock. DDVP utilization to control pest in agriculture, especially in tomato culture was more than other pesticides because it was low-cost and had a broad-spectrum bioactivity (Kurup \& Pillai, 2014). It is a systemic insecticide and acaricide and effective against sucking, chewing and harmful insects and spider mites such as white mites, armyworms, snout moths, leaf and flea beetles, root maggots, white flies, thrips, leafhoppers, diamond back moth in vegetable (Cengiz et al., 2006).

Human might be exposed to DDVP by breathing, eating, or drinking the substance with DDVP residue or by skin contact with soil contaminated with DDVP. It is a small and lipid-soluble molecules and also can be absorbed through route of lungs, gastrointestinal tract, or skin. DDVP leads to allergic reaction in skin, damage to the gastrointestinal tract, respiratory tract, eyes and nervous system. It is classified by the International Agency for Research on Cancer (IARC) as Group 2B, possibly carcinogenic to humans (International Agency for Research on Cancer, 1991).

Tomato (Solanum lycopersicum L.) fruit is one of the most widely consumed and popular fresh vegetables in worldwide. Tomato has various benefits for health and is a major source of the antioxidant in the human diet especially the Mediterranean diet (Pinheiro et al., 2015). However, during culturing, tomato is attracted by various pests such as insects. DDVP is one of the most consumed insecticides in this regard. The existence of DDVP residues in vegetable samples has been reported (Bai et al., 2006).

The Codex has established Maximum Residue Limit (MRL) for DDVP in the range $0.01-15 \mathrm{mg} / \mathrm{kg}$ in various products (Food and Agriculture Organization of the United Nations, 2013). For DDVP in tomato, MRL and pre-harvest interval (as spray) included $0.1-0.5 \mathrm{mg} / \mathrm{kg}$ and 7 days, respectively (Food and Agriculture Organization of the United Nations, 1993). The knowledge of the influence of household processing on the levels of pesticide residues in vegetables is required to reduce dietary exposure (Andrade et al., 2015). Tomatoes are mostly consumed as raw 
and without cooking, therefore, the utilization of one suitable method for the decrease of pesticide residue could be valuable. It is important to estimate the reduction of residues using simple washing procedures.

Washing is the most common processing applied for tomato. It appears that washing loses pesticide residue on vegetable and fruit surface and decreases their concentration in the final product. To increase the influence of washing on the removal of pesticide, chlorine, ozone, and hydrogen peroxide and other compounds were used (Cengiz \& Certel, 2014). Previous study have shown that some processes such as washing, peeling and refrigeration storage, which caused the residue level reduction of DDVP in cucumber (Cengiz et al., 2006). Washing with tap and ozone water and cleaning by ultrasonic significantly reduced the residue level of pesticide in some food commodities (Balawejder et al., 2013; Chen et al., 2013; Kwon et al., 2015; Łozowicka \& Jankowska, 2016). Kwon et al. (2015) found that household processing resulted in the reduction of chlorothalonil, oxadixyl, and thiophanatemethyl residues in tomato. The influence of tomato washing on levels of DDVP residues is a rarely studied issue, and thus far, no reports were found in this regard.

The objective of the current research is to find DDVP residue change in the result of washing with tap and ozonated water, commercial detergent solution and cleaning by ultrasonic.

\section{Materials and methods}

\subsection{Sample collection}

Tomatoes (Better Boy variety) were randomly harvested 24 hours after the application of DDVP. The collected samples were transmitted to the laboratory and immediately removal and extraction operation was performed on them. The detected average residues after spraying DDVP were $3.6 \mu \mathrm{g} / \mathrm{kg}$. The lack of residual pesticides on the tomato samples was verified by residue analysis before the application of DDVP pesticides.

\subsection{Chemicals}

DDVP for analysis was purchased from Sigma-Aldrich (St Louis, USA). Acetone, active carbon, dichloromethane, anhydrous sodium sulfate, and silica gel and other chemical were purchased from Merck (Darmstadt, Germany). All chemicals used were of analytical grade. Solid phase micro-extraction (SPME) was prepared by active carbon and anhydrous sodium sulfate.

\subsection{Preparation of commercial pesticides and application in greenhouse}

Commercial DDVP (Dedevap, 50\% EC) was diluted in water and completely mixed to obtain a sufficient quantity of suspension and applied in the greenhouse area. This pesticide was sprayed on tomato plant cultured in a greenhouse according to the recommended dose $2 \mathrm{~mL}$ DDVP per one $\mathrm{L}$ of water by a skillful technician using a backpack commercial spray. In general, pesticide was utilized once during tomato culture.

\subsection{DDVP removal by tap water}

One Hundred $g$ of the tomato samples were immersed in $1 \mathrm{~L}$ chlorinated tap water with the temperature $20^{\circ} \mathrm{C}$ for 5 , 10 and $15 \mathrm{~min}$. The concentration of chlorine in water was $2 \mathrm{mg} / \mathrm{L}$.

\subsection{DDVP removal by washing with a detergent solution}

Among various detergents, we selected a commercial vegetable disinfection solution, which was consumed widely in Iran for vegetable cleaning. The main composition of the used detergent was benzalkonium chloride (Daro shimi company, Tabriz, Iran). Tomato samples were soaked in distilled water containing different concentrations (1,2 and 3\%) of disinfectant for 5, 10 and $15 \mathrm{~min}$. After the immersion, tomatoes were washed and rinsed by using distilled water and air-dried (temperature of $25^{\circ} \mathrm{C}$ for 2 hours) on the surface of aluminum foil and then analyzed.

\subsection{DDVP removal by ozone water}

Pesticide residues were removed by the ozone generator (ARDA model COG-OM made in France). Ozone was applied in three dosages of 2, 4 and $6 \mathrm{mg} / \mathrm{L}$. For a fine bubble, ozone was diffused through a stainless steel filter. Samples $(0.1 \mathrm{~kg})$ were immersed in ozone water (2 L) for 5, 10 and $15 \mathrm{~min}$.

The temperature of the ozone reactor was set to $15^{\circ} \mathrm{C}$ using a water bath. The ozone level in water was measured by titration (International Ozone Association, 1996).

\subsection{DDVP removal by ultrasonic cleaning}

For this purpose, $0.1 \mathrm{~kg}$ of tomato samples placed into a stainless steel basket and immersed in ultrasonic cleaner. The ultrasonic instrument used in this study was a ELMA model, Germany, with the following characteristics: capacity of $3.7 \mathrm{~cm}^{3}$, dimensions of $30 \times 31 \times 40 \mathrm{~cm}$, a batch flow type; at the frequency of $150 \mathrm{kHz}$, operational temperature of $25 \pm 1^{\circ} \mathrm{C}$ by circulating water in a double jacket cooling array. The ultrasonic operation was carried out in different power modes (100, 200 and $300 \mathrm{~W})$ for 5,10 and $15 \mathrm{~min}$.

\subsection{Recovery studies}

Recovery experiments were conducted by spiking the working standard solutions of DDVP into fresh tomatoes without any pesticide residue at three different fortification levels $(0.5,1.5$ and $3 \mathrm{mg} / \mathrm{kg})$ in triplicate.

The extraction method and GC condition applied to spiked sample was according to mentioned procedure for sprayed sample.

\subsection{DDVP residue analyses}

The procedure applied for the extraction of DDVP residues was based on extraction with a mixture of acetone, dichloromethane and sodium chloride solution (Ambrus et al., 1981). Approximately $1 \mathrm{~kg}$ of the tomato samples was diced, mixed and homogenized. Ten grams of the chopped sample was weighed and transferred to a high-speed blender jar with $40 \mathrm{~mL}$ of acetone and blended for $2 \mathrm{~min}$ at high speed. The homogenate 
was filtered and extracts were collected in $250 \mathrm{ml}$ volumetric flask. The extraction operation conducted at other three times. The obtained extracts under vacuum condition were evaporated and concentrated until approximately $20 \mathrm{~mL}$ by a rotary evaporator (Buchi, German). The concentrated extracts were passed from SPME column. A 50:50 mixture (v/v) of dichloromethane and acetone $(20 \mathrm{~mL})$ was used to elute the DDVP residue. Ten $\mu \mathrm{L}$ of this solution was injected into GC (Liang et al., 2012).

After each experiment, residues on the samples were analyzed and reduction percentages were calculated as compared to unwashed sample. Pesticide residues were analyzed by using a Varian CP-3800 GC (Walnut Creek, Calif., U.S.A.) equipped with a $63 \mathrm{Ni}$ electron capture detector (ECD). The chromatographic separation was achieved by using Varian fused-silica capillary column DB-5, length $30 \mathrm{~m}$; i.d. $0.25 \mathrm{~mm}$; and film thickness $0.25 \mu \mathrm{m}$. The column temperature was raised from $150{ }^{\circ} \mathrm{C}$ (hold $2 \mathrm{~min}$ ) to $280^{\circ} \mathrm{C}$ at $2{ }^{\circ} \mathrm{C} / \mathrm{min}$, the injector temperature was maintained at $220^{\circ} \mathrm{C}$, and the detector temperature was maintained at $300^{\circ} \mathrm{C}$, the flow of carrier gas (nitrogen/air) was applied as $25 \mathrm{~mL} / \mathrm{min}$. The total time for the GC analysis was $43.95 \mathrm{~min}$.

\subsection{Statistical evaluation}

All analyses were performed in triplicate, and the results were presented as mean \pm standard deviation. The statistical analyses of data were performed by using SPSS version 16.0 (IBM SPSS Inc., Chicago, IL). One-way ANOVA was applied for the existence of difference in remained DDVP concentration after various washing methods. Significant means were subjected to analysis by Tukey's test. $P<0.05$ was considered as the significant difference.

\section{Results and discussion}

In this study, the recoveries obtained for the fortification levels $0.5,1.5$ and $3 \mathrm{mg} / \mathrm{kg}$ of DDVP were $92.8,94.6$ and $95.1 \%$, respectively.

Immersing tomato samples for 5, 10 and $15 \mathrm{~min}$ in tap water decreased DDVP level (removal percentage) from $3.6 \mathrm{mg} \mathrm{kg}^{-1}$ to $2.9 \pm 0.1$ (16.8\%), $2.8 \pm 0.1(22.7 \%)$ and $2.5 \pm 0.1 \mathrm{mg} \mathrm{kg}^{-1}$ (30.7\%), respectively. The influence of washing with a commercial disinfectant detergent solution on DDVP removal in tomato is shown in Table 1.

The significant reduction of DDVP concentration was obtained in the tomato samples, which were subjected to these processes. Results showed that between 27.7 and $70.7 \%$ of the initial content of DDVP was removed by washing with a disinfectant detergent solution. It can be observed in Table 2 that the removal of DDVP residues after washing with ozonated water was depended on the contact time and ozone dosage. The increment of ozone dosage from 2 to 4 and then $6 \mu \mathrm{g} \mathrm{kg}^{-1}$ led to the reduction of 33.1, 40.4 and 58.5\% DDVP concentration during $5 \mathrm{~min}$ of washing. However, the same dosage resulted in the reduction of $71.9,88.9$ and $91.9 \%$ this pesticide during $15 \mathrm{~min}$ of washing. Therefore, we could say the increasing of applied ozone dosage was significantly effect on the removal percentages of DDVP.

DDVP fate in tomato after ultrasonic cleaning for 5,10 and $15 \mathrm{~min}$ has been presented in Table 3. DDVP residues were effectively reduced by ultrasonic cleaning. By the increment of ultrasonic

Table 1. Effect of washing with a commercial disinfectant detergent solution on concentration $\left(\mathrm{mg} \mathrm{Kg}^{-1}\right)$ and removal percentage of DDVP in tomato.

\begin{tabular}{|c|c|c|c|c|}
\hline \multirow{3}{*}{ Washing time (min) } & \multirow{3}{*}{$\begin{array}{c}\text { Concentration of DDVP in } \\
\text { unwashed tomato }\end{array}$} & \multicolumn{3}{|c|}{ Concentration of DDVP in washed tomato } \\
\hline & & \multicolumn{3}{|c|}{ Disinfectant detergent concentration (g/100 g water) } \\
\hline & & 1 & 2 & 3 \\
\hline 5 & 3.6 & $\begin{array}{l}2.6 \pm 0.1^{\mathrm{Aa}} \\
(27.7 \%)\end{array}$ & $\begin{array}{l}1.9 \pm 0.1^{\mathrm{Ba}} \\
(46.8 \%)\end{array}$ & $\begin{array}{l}1.5 \pm 0.1^{\mathrm{Ca}} \\
(59.5 \%)\end{array}$ \\
\hline 10 & 3.4 & $\begin{array}{c}2.1 \pm 0.1^{\mathrm{Ab}} \\
(38.0 \%)\end{array}$ & $\begin{array}{c}1.9 \pm 0.0^{\mathrm{Aa}} \\
(43.3 \%)\end{array}$ & $\begin{array}{c}1.35 \pm 0^{\mathrm{Ba}} \\
(60.5 \%)\end{array}$ \\
\hline 15 & 3.5 & $\begin{array}{c}1.2 \pm 0.0^{\mathrm{Ac}} \\
(66.8 \%)\end{array}$ & $\begin{array}{c}1.1 \pm 0.0^{\mathrm{ABb}} \\
(69.3 \%)\end{array}$ & $\begin{array}{c}1.0 \pm 0.1^{\mathrm{Bb}} \\
(70.7 \%)\end{array}$ \\
\hline
\end{tabular}

Different superscript capital letters (A-C) within a row indicate statistically significant differences $(P<0.05)$ among values. Different superscript small letters (a-c) within a column indicate statistically significant differences $(\mathrm{P}<0.05)$ among values.

Table 2. Effect of ozonated water on concentration $\left(\mathrm{mg} \mathrm{Kg}^{-1}\right)$ and removal percentage of DDVP in tomato.

\begin{tabular}{|c|c|c|c|c|}
\hline \multirow{3}{*}{ Washing time (min) } & \multirow{3}{*}{$\begin{array}{c}\text { Concentration of DDVP in } \\
\text { unwashed tomato }\end{array}$} & \multicolumn{3}{|c|}{ Concentration of DDVP in washed tomato } \\
\hline & & \multicolumn{3}{|c|}{ Ozone dosage $\left(\mathrm{mg} \mathrm{L}^{-1}\right)$} \\
\hline & & 2 & 4 & 6 \\
\hline 5 & 3.7 & $\begin{array}{c}2.5 \pm 0.1^{\mathrm{Aa}} \\
\quad(32.1)\end{array}$ & $\begin{array}{c}2.2 \pm 0.0^{\mathrm{Ba}} \\
(40.4 \%)\end{array}$ & $\begin{array}{c}1.5 \pm 0.1^{\mathrm{Ca}} \\
(58.5 \%)\end{array}$ \\
\hline 10 & 3.6 & $\begin{array}{c}1.5 \pm 0.0^{\mathrm{Ab}} \\
(58.9 \%)\end{array}$ & $\begin{array}{c}0.8 \pm 0.0^{\mathrm{Bb}} \\
(78.2 \%)\end{array}$ & $\begin{array}{c}0.4 \pm 0.0^{\mathrm{Cb}} \\
(89.5 \%)\end{array}$ \\
\hline
\end{tabular}

Different superscript capital letters (A-C) within a row indicate statistically significant differences $(P<0.05)$ among values. Different superscript small letters $(\mathrm{a}-\mathrm{c})$ within a column indicate statistically significant differences $(P<0.05)$ among values. 
Table 3. Effect of ultrasonic power on concentration $\left(\mathrm{mg} \mathrm{Kg}^{-1}\right)$ and removal percentage of DDVP in tomato.

\begin{tabular}{|c|c|c|c|c|}
\hline \multirow{3}{*}{ Washing time (min) } & \multirow{3}{*}{$\begin{array}{c}\text { Concentration of DDVP in } \\
\text { unwashed tomato }\end{array}$} & \multicolumn{3}{|c|}{ Concentration of DDVP in washed tomato } \\
\hline & & \multicolumn{3}{|c|}{ Ultrasonic power $(\mathrm{W})$} \\
\hline & & 100 & 200 & 300 \\
\hline 5 & 3.2 & $\begin{array}{c}2.9 \pm 0.1^{\mathrm{Aa}} \\
(13.3 \%)\end{array}$ & $\begin{array}{c}2.2 \pm 0.1^{\mathrm{Ba}} \\
(30.6 \%)\end{array}$ & $\begin{array}{c}1.9 \pm 0.1^{\mathrm{Ca}} \\
(42.1 \%)\end{array}$ \\
\hline 10 & 3.4 & $\begin{array}{c}1.5 \pm 0.1^{\mathrm{Ab}} \\
(56.7 \%)\end{array}$ & $\begin{array}{c}1.3 \pm 0.1^{\mathrm{Bb}} \\
(61.7 \%)\end{array}$ & $\begin{array}{l}1.0 \pm 0^{\mathrm{Cb}} \\
(71.6 \%)\end{array}$ \\
\hline 15 & 3.1 & $\begin{array}{c}0.97 \pm 0.1^{A c} \\
(68.6 \%)\end{array}$ & $\begin{array}{c}0.62 \pm 0.0^{\mathrm{Bc}} \\
(79.9 \%)\end{array}$ & $\begin{array}{c}0.3 \pm 0.0^{\mathrm{Cc}} \\
(89.0 \%)\end{array}$ \\
\hline
\end{tabular}

Different superscript capital letters $(\mathrm{A}-\mathrm{C})$ within a row indicate statistically significant differences $(P<0.05)$ among values. Different superscript small letters $(\mathrm{a}-\mathrm{c})$ within a column indicate statistically significant differences $(P<0.05)$ among values.

time and power, DDVP removal increased. The increment of ultrasonic power from 100 to $300 \mathrm{~W}$ caused the removal level to increase from 13.31 to $42.11 \%$ after 5 min washing, from 56.7 to $71.5 \%$ after 10 min washing and from 68.6 to $88.9 \%$, after 15 min washing.

The uncontrolled application of pesticides and neglect of harvest intervals result in the occurrence of some pesticide residues in various food types (Heleno et al., 2015). Information on the influence of postharvest different processes including washing on the fate of pesticide residues in food substances is highly important from both regulatory and public concern perspectives. Washing with water or detergent could remove some pesticide residues in fruit and vegetables. The efficiency of the washing procedures on the pesticide removal of vegetable and fruits depends on the formulation and application method of the pesticide, initial residue amount, nature of the used washing solution, the physicochemical properties of the pesticide such as solubility, volatility, hydrolytic rate constants and water-octanol partition coefficient, contact surface area, nature and attributes of the food substance, length of time of contact of food and washing solution as well as pesticide action mechanism, i.e. surface or systematic pesticide, physical place of the pesticide residue and washing time after pesticide spraying (Al-Taher et al., 2013). Generally, the efficiency of washing treatments for the removal of pesticide residue transferred from vegetable or fruit surface to the inside is lower (Keikotlhaile et al., 2010; Al-Taher et al., 2013). The previous study by Liang et al. (2014) found that washing by tap water could effectively decrease the pesticide residues in fruit.

It is possibility for the pesticide residue during processing either to increase or to decrease (Keikotlhaile et al., 2010). Our results showed washing with tap water reduced a small amount from DDVP while washing with a disinfectant detergent solution could remove $71.1 \%$ of DDVP. It seemed that DDVP residue is dissolved in the wax layer of tomato and could not be easily eliminated by plain washing. A gradual increase was observed in the percentage of removal due to the increment of the concentration of detergent solution. In most research conducted on the change of pesticide residue after vegetable and fruit harvest, washing was the most studied method of processing (Guardia-Rubio et al., 2007; Keikotlhaile et al., 2010; Al-Taher et al., 2013). Disinfectant detergent utilization for washing vegetables such as tomato was a good practice that was applied in some countries.

The results of the current research were different from a study conducted by Liang et al. (2012) who reported that washing with tap water reduced $75 \%$ of DDVP level in cucumber. These authors found that washing with $5 \%$ sodium bicarbonate solution (for $20 \mathrm{~min}$ ) in comparison with tap water and different detergent solutions had the greatest loss (98.8\%) in cucumber DDVP concentration. After spraying of pesticide on fruit and vegetables, most of their residues are confined to the outer surfaces; therefore, this is the reasonable that the majority of the residues are removed by washing, peeling, or treatments with detergent solutions (Bajwa \& Sandhu, 2014). The removal of pesticides from the surface of fruit and vegetable is due to their solubility in water.

In recent years, the application of ozone for the oxidation of residual pesticides on agricultural products is taken into consideration (Kusvuran et al., 2012). Ozone has potential oxidizing capacity and is classified as generally recognized as safe (GRAS) compound (Balawejder et al., 2013). Among different treatments applied in this research, ozonated water $(6 \mathrm{mg} / \mathrm{L})$ had the highest impact on DDVP residue and almost $91.38 \%$ of its concentration in the samples were removed after $15 \mathrm{~min}$. The reported removal percentages due to ozone utilization for some pesticides were higher than that found in the recent research. Ozonation for $5 \mathrm{~min}$ was completely removed chlorothalonil and chlorpyrifos ethyl residues on orange and grapefruit matrices (Kusvuran et al., 2012). Our results are similar to other studies. Chen et al. (2013) designed a machine for pesticide residues remove from Chinese white cabbage and green-stem bok choy. In the ozone production rate $500 \mathrm{mg} / \mathrm{h}$, they reported the reduction of 75 and $77 \%$ for chlorfluazuron and chlorothalonil, repetitively (Chen et al., 2013). Heleno et al. (2015) showed that $60 \%$ of chlorothalonil from table grapes (pulp and skin) was removed by ozone treatment.

Ultrasonic cleaning is a new technology applied to wash fruit and vegetables in the food industry. We found the DDVP removal depended on ultrasonic time and power. When ultrasonic power was $300 \mathrm{~W}$, DDVP residue was reduced to $90.41 \%$ after $15 \mathrm{~min}$. In the previous studies, similar results have been reported. Lozowicka et al. (2016) indicated that ultrasonic cleaning could be an effective treatment for the removal of 16 pesticides in raw strawberries reducing $91.2 \%$ of the residue. Our results 
were different from other studied due to type of vegetable and pesticide. Liang et al. (2012) reported the reduction of $49.8 \%$ for DDVP residue in cucumber samples subjected to ultrasonic cleaning for $20 \mathrm{~min}$. These authors did not mention ultrasonic power. The ultrasonic waves in the water create cavitation; rapid formation and violent collapse of micron-sized bubbles in a liquid medium, causing high cleaning power, which could eliminate the pesticide residue (Valero et al., 2007).

\section{Conclusion}

In conclusion, washing with ozonated water, a detergent solution and ultrasonic cleaning could significantly reduce DDVP residue and dietary exposure. The gradual increase in the percentage of the removal was observed due to the increment of ozone dosage, concentration of detergent solution, power of ultrasonic and processing time. Among different treatments, ozonated water had the highest DDVP removal. The highest reduction of DDVP level (91.9\%) was obtained after $15 \mathrm{~min}$ of washing with water containing $6 \mathrm{mg}$ ozone /L.

\section{Acknowledgements}

This work was supported by the Research and Technology Vice-Chancellor of Hamadan University of Medical Sciences and Health Services under Grant 9408074326.

\section{References}

Al-Taher, F., Chen, Y., Wylie, P., \& Cappozzo, J. (2013). Reduction of pesticide residues in tomatoes and other produce. Journal of Food Protection, 76(3), 510-515. PMid:23462090. http://dx.doi. org/10.4315/0362-028X.JFP-12-240.

Ambrus, A., Lantos, J., Visi, E., Csatlos, I., \& Sarvari, L. (1981). General method for determination of pesticide residues in samples of plant origin, soil, and water. I. Extraction and cleanup. Journal - Association of Official Analytical Chemists, 64(33), 733-742.

Andrade, G. C. R. M., Monteiro, S. H., Francisco, J. G., Figueiredo, L. A., Rocha, A. A., \& Tornisielo, V. L. (2015). Effects of types of washing and peeling in relation to pesticide residues in tomatoes. Journal of the Brazilian Chemical Society, 26, 1994-2002.

Bai, Y., Zhou, L., \& Wang, J. (2006). Organophosphorus pesticide residues in market foods in Shaanxi area, China. Food Chemistry, 98(2), 240-242. http://dx.doi.org/10.1016/j.foodchem.2005.05.070.

Bajwa, U., \& Sandhu, K. S. (2014). Effect of handling and processing on pesticide residues in food: a review. Journal of Food Science and Technology, 51(2), 201-220. PMid:24493878. http://dx.doi. org/10.1007/s13197-011-0499-5.

Balawejder, M., Antos, P., \& Sadlo, S. (2013). Potential of ozone utilization for reduction of pesticide residue in food of plant origin: a review. Roczniki Panstwowego Zakladu Higieny, 64(1), 13-18. PMid:23789307.

Cengiz, M. F., \& Certel, M. (2014). Effects of chlorine, hydrogen peroxide, and ozone on the reduction of mancozeb residues on tomatoes. Turkish Journal of Agriculture and Forestry, 38, 371-376. http://dx.doi.org/10.3906/tar-1307-14.

Cengiz, M. F., Certel, M., \& Göçmen, H. (2006). Residue contents of DDVP (Dichlorvos) and diazinon applied on cucumbers grown in greenhouses and their reduction by duration of a pre-harvest interval and post-harvest culinary applications. Food Chemistry, 98(1), 127-135. http://dx.doi.org/10.1016/j.foodchem.2005.05.064.
Chen, J. Y., Lin, Y. J., \& Kuo, W. C. (2013). Pesticide residue removal from vegetables by ozonation. Journal of Food Engineering, 114(3), 404-411. http://dx.doi.org/10.1016/j.jfoodeng.2012.08.033.

Food and Agriculture Organization of the United Nations - FAO. (1993). Dichlorvos. Rome: FAO. Retrieved from http://www.fao.org

Food and Agriculture Organization of the United Nations - FAO. (2013). Codex alimentarius: pesticide residues in food and feed-maximum residue limits for dichlorvos. Rome: FAO. Retrieved from http:// www.codexalimentarius.net

Guardia-Rubio, M., Ayora-Canada, M. J., \& Ruiz-Medina, A. (2007). Effect of washing on pesticide residues in olives. Journal of Food Science, 72(2), C139-C143. PMid:17995829. http://dx.doi. org/10.1111/j.1750-3841.2006.00252.x.

Heleno, F. F., Queiroz, M. E. L. R. d., Neves, A. A., Faroni, L. R. A., Sousa, F. A. d., \& Oliveira, A. F. d. (2015). Ozone treatment for the removal of residual chlorothalonil and effects on the quality of table grapes. Journal of the Brazilian Chemical Society, 26, 687-694.

International Agency for Research on Cancer - IARC. (1991). Monographs on the evaluation of carcinogenic risks to humans: occupational exposures in insecticide application, and some pesticides: dichlorvos. (Vol. 53). Geneva: UN World Health Organization.

International Ozone Association - IOA. (1996). IOA Standardisation Committee 001/96: iodometric method for the determination of ozone in a process gas. Brussels: IOA. Revised Standardized Procedure 001/96.

Keikotlhaile, B. M., Spanoghe, P., \& Steurbaut, W. (2010). Effects of food processing on pesticide residues in fruits and vegetables: A meta-analysis approach. Food and Chemical Toxicology, 48(1), 1-6. PMid:19879312. http://dx.doi.org/10.1016/j.fct.2009.10.031.

Kurup, S., \& Pillai, A. K. (2014). A simple and sensitive kinetic method for determination of dichlorvos. International Journal of Chem Tech Research, 6(5), 2933-2940.

Kusvuran, E., Yildirim, D., Mavruk, F., \& Ceyhan, M. (2012). Removal of chloropyrifos ethyl, tetradifon and chlorothalonil pesticide residues from citrus by using ozone. Journal of Hazardous Materials, 241-242, 287-300. PMid:23058925. http://dx.doi.org/10.1016/j. jhazmat.2012.09.043.

Kwon, H., Kim, T. K., Hong, S. M., Se, E. K., Cho, N. J., \& Kyung, K. S. (2015). Effect of household processing on pesticide residues in field-sprayed tomatoes. Food Science and Biotechnology, 24(1), 1-6. http://dx.doi.org/10.1007/s10068-015-0001-7.

Liang, Y., Liu, Y., Ding, Y., \& Liu, X. J. (2014). Meta-analysis of food processing on pesticide residues in fruits. Food Additives \& Contaminants. Part A, Chemistry, Analysis, Control, Exposure \& Risk Assessment, 31(9), 1568-1573. PMid:25005864. http://dx.doi. org/10.1080/19440049.2014.942708.

Liang, Y., Wang, W., Shen, Y., Liu, Y., \& Liu, X. J. (2012). Effects of home preparation on organophosphorus pesticide residues in raw cucumber. Food Chemistry, 133(3), 636-640. http://dx.doi. org/10.1016/j.foodchem.2012.01.016.

Łozowicka, B., \& Jankowska, M. (2016). Comparison of the effects of water and thermal processing on pesticide removal in selected fruit and vegetables. Journal of Elementology, 21(1), 99-111.

Lozowicka, B., Jankowska, M., Hrynko, I., \& Kaczynski, P. (2016). Removal of 16 pesticide residues from strawberries by washing with tap and ozone water, ultrasonic cleaning and boiling. Environmental Monitoring and Assessment, 188(1), 51. PMid:26694708. http:// dx.doi.org/10.1007/s10661-015-4850-6.

Miele, A., Rizzon, L. A., Queiroz, S. C. N. d., \& Gianello, C. (2015). Physicochemical composition, minerals, and pesticide residues in organic grape juices. Food Science and Technology, 35(1), 120-126. 
Nakano, V. E., Kussumi, T. A., Lemes, V. R. R., Kimura, I. A., Rocha, S. B., Alaburda, J., Oliveira, M. C. C., Ribeiro, R. A., Faria, A. L. R., \& Waldhelm, K. C. (2016). Evaluation of pesticide residues in oranges from São Paulo, Brazil. Food Science and Technology (Campinas), 36(1), 40-48. http://dx.doi.org/10.1590/1678-457X.6837.

Pinheiro, J., Alegria, C., Abreu, M., Sol, M., Gonçalves, E. M., \& Silva, C. L. M. (2015). Postharvest quality of refrigerated tomato fruit (solanum lycopersicum, cv. zinac) at two maturity stages following heat treatment. Journal of Food Processing and Preservation, 39(6), 697-709. http://dx.doi.org/10.1111/jfpp.12279.

Valero, M., Recrosio, N., Saura, D., Muñoz, N., Martí, N., \& Lizama, V. (2007). Effects of ultrasonic treatments in orange juice processing. Journal of Food Engineering, 80(2), 509-516. http://dx.doi.org/10.1016/j. jfoodeng.2006.06.009. 